\title{
Insurance-Based Investment Products: Regulatory Responses and Policy Issues
}

\author{
Michele Siri
}

\section{Introduction}

Investor protection can be defined as the set of rules and principles expected to preserve the interests and the rights of a person in its role as the investor or the defensive protection of the vulnerable investor against unscrupulous market participants. ${ }^{1}$ The aim of investor protection regulation is to allow investors to make informed financial decisions which are better aligned with their interests and profile. Following the financial turmoil in 2007, and considered the increasing complexity of financial markets, the EU has strengthened its regulatory efforts in setting a proper level of protection and transparency in the area of investment services. ${ }^{2}$ In particular, by introducing the Directive on Markets in Financial Instruments (MiFID), ${ }^{3}$ the related Markets in Financial Instruments Regulation (MiFIR), ${ }^{4}$ the Insurance Distribution Directive (IDD) ${ }^{5}$ and the Regulation on key information documents for packaged retail and insurance-based investment products (PRIIPs), ${ }^{6}$ the EU has

${ }^{1}$ Clarck (1976), p. 26.

${ }^{2}$ Colaert (2017a), pp. 229-244; Moloney (2015), pp. 736-765; Moloney (2010).

${ }^{3}$ Directive 2004/39/EC (MiFID I), recently revised by Directive 2014/65/E (MiFID II). See Liverse (2016), p. 45. See also Moloney (2014), chapter IX.

${ }^{4}$ Regulation 648/2012/EU.

${ }^{5}$ Directive 2016/97/EU. See Hofmann et al. (2018), p. 740 ss.; Köhne and Brömmelmeyer (2018), p. 704 ss.; Ramharter (2016), p. 221 ss.

${ }^{6}$ EU Regulation 1286/2014/EU of 26 November 2014 on key information documents for packaged retail and insurance-based investment products (PRIIPs).

M. Siri $(\bowtie)$

University of Genoa, Law Department, Genoa, Italy

e-mail: michele.siri@unige.it

P. Marano, K. Noussia (eds.), Insurance Distribution Directive, AIDA Europe

Research Series on Insurance Law and Regulation 3,

https://doi.org/10.1007/978-3-030-52738-9_5 
recently provided the main—sometimes overlapping — criteria to be followed by financial intermediaries in conducting their activities.

The IDD plays a significant role in the promotion of consumer protection within the distribution of insurance products across the EU, especially considering that MiFID II does not cover the distribution of insurance-based products. In particular, the IDD ensures greater transparency by insurance distributors in relation to the price and costs of their products but also provides higher standards as regards product information and conduct of business (COB) rules. In performing this function, the IDD provides many rules echoing the corresponding MiFID II rules. However, many differences persist and present a risk of segmentation and regulatory arbitrage. ${ }^{7}$ Moreover, while MiFID II aspires to a maximum harmonisation, the IDD expressly aims at a minimum harmonization (as stated in Recital 3), which means that any Member State can impose stricter rules to protect customers. The IDD has been supplemented by two delegated regulations - based on the European Insurance and Occupational Pensions Authority (EIOPA) Technical Advice to the Commission ${ }^{8}$ concerning product oversight and governance requirements for insurance undertakings and insurance distributors, information requirements and conduct of business rules.

The IDD aims explicitly to harmonise national provisions concerning insurance and reinsurance distribution across the European Union, and targets not only-as in the past-insurance brokers or intermediaries, but several types of persons or institutions which distribute insurance-based investment products (IBIPs) to third parties, such as agents, 'bancassurance' operators, insurance undertakings, travel agents and car rental companies. However, customers - regardless of the distribution channel-should benefit from the same level of protection and equal treatment. In particular, in line with the MiFID II regime for financial instruments and structured deposits, within the IDD regime customer protection is ensured by specific provisions concerning the conduct of business rules and product governance requirements. ${ }^{9}$ In this regard, since the IDD empowers the Commission to adopt specific Delegated Acts concerning such requirements, on February 2016, the European Commission requested the EIOPA for its technical advice for the development of IDD Delegated Acts. Two Commission Delegated Regulations were published in autumn 2017 and specifically targeted conduct on business rules for IBIPs and product and oversight governance applicable to all insurance contracts, including IBIPs. ${ }^{10}$

\footnotetext{
${ }^{7}$ Kern (2018), p. 31; Colaert (2017b), pp. 589 ss.

${ }^{8}$ EIOPA 17/048, Technical Advice on Insurance Distribution Directive (1 February 2017). See Noussia (2019), pp. 119-136.

${ }^{9}$ Rokas and Siafarika (2019), p. 3 ss.

${ }^{10}$ Respectively, Commission Delegated Regulation (EU) 2017/2359 of 21 September 2017 supplementing Directive (EU) 2016/97 of the European Parliament and of the Council with regard to information requirements and conduct of business rules applicable to the distribution of insurance-based investment products; and Commission Delegated Regulation (EU) 2017/2358 of 21 September 2017 supplementing Directive (EU) 2016/97 of the European Parliament and of the
} 


\section{Disclosure of Information}

Traditionally, product information has been sectoral or even product-specific, with a change of approach only recently represented by the PRIIPs Regulation. ${ }^{11}$ In the PRIIPS Regulation, the Key Information Document (or KID) is a basic information leaflet on the essential features of a wide range of packaged retail and insurancebased investment products such as structured products, insurance-based investment products or investment funds that retail investors can buy directly from manufacturers of those products or indirectly through financial intermediaries, by means of the internet, or otherwise. ${ }^{12}$

The PRIIPs KID must be made available to retail investors prior to any sale, either in a paper format or through a durable medium or a website. The KID is required to contain pre-contractual information to help the retail investor understand the features of the product and compare it with other products. This includes comprehensive information on the product's objectives and how it will achieve them, on its riskreward profile (including maximum possible loss) and the assumptions on which this is based, on all costs to be directly or indirectly borne by the retail investor, and on the product's recommended holding period. ${ }^{13}$ By capturing a wide variety of retail investments, PRIIPs seeks to ensure comparability across and within sectors as well as across borders, without imposing specific requirements in relation to business models, product designs or legal forms.

Solvency II contains a series of pre-contractual disclosure requirements which have to be complied with by insurance undertakings. These include general information about the applicable law and the insurance company and, in the case of life insurance, a series of basic elements of information on the contract, such as coverage, terms of the contract, conditions for termination, payment of premiums, an indication of surrender and paid-up values, tax arrangements, and rules on complaint handling. The insurance undertaking must also inform policyholders about their right to cancel the contract within a cooling-off period. ${ }^{14}$

The IDD provides a set of basic disclosure rules which apply to the distribution of all insurance products. These require the provision of information to the customer about the insurance intermediary or insurance undertaking selling the product, about the provision of advice and about the remuneration received in relation to the insurance contract. The insurance distributor must also gather information from

Council with regard to product oversight and governance requirements for insurance undertakings and insurance distributors.

${ }^{11}$ Colaert (2019), p. 303 ss.

${ }^{12}$ Kyriaki and Siri (2019), p. 39 ss.; Colaert (2016).

${ }^{13}$ Articles 5-12 PRIIPs Regulation. See also for further details about the KIID's content, Commission Delegated Regulation (EU) 2017/65313. As far IBIPs are concerned, see EIOPA, Costs and past performance, 2020 Report, April 2020.

${ }^{14}$ Articles $183 \mathrm{ff}$ Solvency II. 
the customer in order to establish his/her insurance demands and needs. ${ }^{15}$ If the insurance product sold is an IBIPs, the insurance intermediary or insurance undertaking has to comply with the additional requirements set out in the IDD. ${ }^{16}$ These requirements are largely aligned to those of MiFID II and include disclosure of all costs and charges in an aggregated form under the same conditions as provided in MiFID II. ${ }^{17}$ However, contrary to MiFID II, ${ }^{18}$ the requirements set out in the IDD are not further detailed in Level 2 legislation.

\section{Conflicts of Interest}

The IDD and its delegated regulation ${ }^{19}$ follow MiFID II provisions and those of its delegated regulation. ${ }^{20}$ Neither Article 23 of MiFID II or Article 28 of the IDD defines or prohibits conflicts of interest. However, in the relevant delegated regulations, we find provisions specifying certain situations which should be taken into account in the assessment of conflicts of interest, ${ }^{21}$ and the requirement for insurance intermediaries and insurance undertakings to establish, implement and maintain specific conflicts of interest policy to be followed for the identification, prevention and management of such conflicts of interest. ${ }^{22}$ In particular, insurance intermediaries and insurance undertakings shall assess whether they, a relevant person or any person directly or indirectly linked to them by control, have an interest in the outcome of the insurance distribution activities, in the event such an interest: (a) is distinct from the customer's or potential customer's interest in the outcome of the insurance distribution activities; and (b) has the potential to influence the outcome of the distribution activities to the detriment of the customer. ${ }^{23}$

As for the conflicts of interest policy, this should include the circumstancesrelated to the specific insurance distribution activity-which constitute or may give rise to a conflict of interest which could damage customers' interest, as well as the procedures to be followed and the measure to be adopted for the management of such

\footnotetext{
${ }^{15}$ Articles $18 \mathrm{ff}$ IDD.

${ }^{16}$ Articles 26ff IDD. Please see Noussia and Siri (2019), p. 39 ss.

${ }^{17}$ Article 24 MiFID II. About MiFID II disclosure rules, among others: Della Negra (2019), p. 34ff.

${ }^{18}$ Articles 44ff Commission Delegated Regulation (EU) 2017/565.

${ }^{19}$ Articles 3-7 Commission Delegated Regulation (EU) 2017/2359.

${ }^{20}$ The above-mentioned Commission Delegated Regulation (EU) 2017/565. See also the Explanatory Memorandum, Commission Delegated Regulation (EU) 2017/2359, p. 3.

${ }^{21}$ Article 3 Commission Delegated Regulation (EU) 2017/2359 and Article 33 Commission Delegated Regulation (EU) 2017/565.

${ }^{22}$ Article 4 Commission Delegated Regulation (EU) 2017/2359. For investment firms, $c f$. Article 34 Commission Delegated Regulation (EU) 2017/565.

${ }^{23}$ Article 3(2) Commission Delegated Regulation (EU) 2017/2359.
} 
conflicts. $^{24}$ The policy should be assessed and periodically reviewed, on an at least annual basis, and amended in case of any deficiency. ${ }^{25}$

As regards insurance intermediaries, who are under a contractual obligation to conduct the insurance distribution business exclusively with one or more insurance undertakings, EIOPA has clarified that the conflicts of interest policy remain a requirement under the responsibility of that intermediary. ${ }^{26}$ EIOPA considers it essential that intermediaries who distribute exclusively on behalf of one or more insurance undertakings are required to establish, implement and maintain an efficient conflicts of interest policy, set out in writing and suited to their size and organisation and the nature, scale and complexity of their business in accordance with Article 4 (1) of Delegated Regulation 2017/2359. This requirement "does not prohibit intermediaries who distribute exclusively on behalf of one or more insurance undertakings, from receiving assistance and guidance from an insurance undertaking to which they are tied, in developing a conflicts of interest policy". However, EIOPA holds that the regulatory responsibility of establishing, implementing and operating the policy remains with the insurance intermediary.

As in MiFID II, ${ }^{27}$ the disclosure of a conflict of interest should be limited to situations in which the organisational and administrative arrangements are insufficient to prevent the risks of damage to the interests of the customer. ${ }^{28}$ In such a case, the disclosure should be made on a durable medium and include sufficient detail, ${ }^{29}$ which means that it should provide a specific description of the conflicts of interest, explain its general nature, sources, and associated risks for consumers, and state that the organizational and administrative arrangements established within the conflicts of interest policy are not sufficient to ensure, with reasonable confidence, the prevention of such risks. ${ }^{30}$ Finally, the senior management of the insurance distributors should receive, at least annually, written reports on the situations in which a conflict of interest arose, and of these the insurance intermediary of undertaking should keep a record. ${ }^{31}$

In EIOPA's view, ${ }^{32}$ an insurance intermediary or insurance undertaking is not exempted from further managing conflicts of interests if it discloses the conflicts of interest to the consumer. The legal basis for such conclusion is the Recital 5 of

\footnotetext{
${ }^{24}$ Article 4(2) Commission Delegated Regulation (EU) 2017/2359.

${ }^{25}$ Article 7(1) and Recital 5 Commission Delegated Regulation (EU) 2017/2359. Cf. Article 34 (5) Commission Delegated Regulation (EU) 2017/565.

${ }^{26}$ EIOPA, Q\&A on Regulation (2018), No. 1622.

${ }^{27}$ Article 34(4) of the Commission Delegated Regulation (EU) 2017/565.

${ }^{28}$ Article 6(1) and Recital 5 Commission Delegated Regulation (EU) 2017/2359.

${ }^{29}$ Article 28(3) IDD.

${ }^{30}$ Article 6(2) and Recital 5 Commission Delegated Regulation (EU) 2017/2359.

${ }^{31}$ Article 7(2) and Recital 5 Commission Delegated Regulation (EU) 2017/2359. Cf. Article 35 Commission Delegated Regulation (EU) 2017/565.

${ }^{32}$ EIOPA, Q\&A on Regulation (2018), No. 1625. See also No. 1627 as regards to the application of proportionality in relation to the measures set out in the IDD for managing conflicts of interest.
} 
Delegated Regulation 2017/2359 which clarifies that the disclosure of conflicts of interest by an insurance intermediary or an insurance undertaking cannot exempt it from the obligation to maintain and operate the organisational and administrative arrangements that are the most effective means of preventing damage to customers. EIOPA considers, being "disclosure [...] a measure of last resort", that the insurance intermediary or insurance undertaking has to take "all reasonable steps to prevent the conflicts of interest from adversely affecting the interests of its customers and only when the conflicts of interests cannot be prevented, disclosure of the conflicts of interest to the customer is expected". As part of the disclosure, EIOPA considers it important that "the customer is advised that organisational and administrative measures established to prevent or manage conflicts of interest are not sufficient to ensure, with reasonable confidence, that risks of damage" to the interests of the customer will be prevented. Such a report is not addressed to the insurance undertaking, given the reference in Art. 7 only to report on conflicts of interest to their senior management of the intermediary.

\section{Inducements}

According to the IDD, the insurance intermediary should inform the client whether, in relation to the insurance contract, any inducement, ${ }^{33}$ i.e. any fee, commission or non-monetary benefit paid or provided by any party except the customer, is paid. The payment of inducements is allowed (and insurance intermediaries and insurance undertakings are regarded as fulfilling their obligations) if it '(a) does not have a detrimental impact on the quality of the relevant service to the customer, and (b) does not impair compliance with the insurance intermediary's or insurance undertaking's duty to act honestly, fairly and professionally in accordance with the best interests of its customers' ${ }^{34}$ This seems a less stringent discipline compared to that provided in MiFID II, which imposes specific bans and strict limitations to fees and commission paid, especially in connection with independent financial advice and portfolio management. ${ }^{35}$

However, inducements rules in the insurance sector appear stricter when looking at EIOPA's interpretation of IDD provisions: in fact, any sort of rebates can be considered an inducement, irrespective of their origin. Thus, even receiving rebates with different rates from fund managers is covered and such rebates must be assessed under Article 29(2) IDD to ensure that they do not have a detrimental impact on the quality of the relevant service to the customer and that do not impair compliance with the insurance intermediary's or insurance undertaking's duty to act honestly,

\footnotetext{
${ }^{33}$ Article 19(1)(e) IDD. About this part, please see Noussia and Siri (2019), p. $47 \mathrm{ff}$.

${ }^{34}$ Article 29(2) IDD.

${ }^{35}$ Art 24(7), (8) and (9) MiFID II. For a comparison between MiFID II and IDD as regards inducements, see Colaert and Incalza (2019), p. 377.
} 
fairly and professionally in accordance with the best interests of its customers. ${ }^{36}$ Furthermore, a rebate should be assessed in accordance with Article 29(2), IDD regardless of whether a personal recommendation is provided. ${ }^{37}$

Moreover, EIOPA states that the insurance undertaking which receives the rebate is obliged to consider "all relevant factors which may increase or decrease the risk of a detrimental impact on the quality of the relevant service to the customer, and which have potential to impair compliance with the insurance undertakings duty to act honestly, fairly and professionally in accordance with the best interests of its customers, including the fact that different rates are received from fund managers". Insurance undertakings must also take into account EIOPA's Opinion on monetary incentives and remuneration between providers of asset management services and insurance undertakings ${ }^{38}$ in which the risk of customer detriment related to the practice of receiving rebates from asset managers is addressed, including the application of the Product Oversight and Governance requirements. ${ }^{39}$

As requested by the IDD, ${ }^{40}$ the Commission further specified in a delegated act the criteria for assessing whether inducements paid or received increase the risk of a detrimental impact on the quality of the relevant service. ${ }^{41}$ In particular, an inducement has to be considered to have a detrimental impact on the quality of the relevant service to the customer when "it is of such a nature and scale that it provides an incentive to carry out insurance distribution activities in a way that is not in compliance with the obligation to act honestly, fairly and professionally in accordance with the best interests of the customer". "Furthermore, insurance distributors should conduct an overall analysis taking into account "all relevant factors which may increase or decrease the risk of a detrimental impact on the quality of the relevant service to the customer', as well as 'any organizational measures taken by the insurance intermediary or insurance undertaking carrying out distribution activities to prevent the risk of detrimental impact". 43

The insurance intermediary or insurance undertaking is required to consider the amount of inducement being paid in comparison to the value of the product or service being provided. EIOPA holds that insurance intermediaries and insurance undertakings need to consider whether "the customer is receiving value for the

\footnotetext{
${ }^{36}$ EIOPA, Q\&A on Regulation (2018), No. 1630.

${ }^{37}$ EIOPA Q\&A on Regulation (2018), No. 1633.

${ }^{38}$ EIOPA, Opinion on Monetary Incentives and Remuneration Between Providers of Asset Management Services and Insurance Undertakings, 17/295 (2017).

${ }^{39}$ EIOPA Q\&A on Regulation (2018), No. 1632 and 1633. About product governance, see in this volume Marano P, The Contribution of Product Oversight and Governance (POG) to the Single Market: A Set of Organizational Rules for Business Conduct. In the MiFID II/MiFIR legislation, see Busch (2016), p. 123 ss. As regards to the EU insurance supervisory law, see also Dreher (2019), p. 79 ss.

${ }^{40}$ Article 29(4) IDD.

${ }^{41}$ Article 8 Commission Delegated Regulation (EU) 2017/2359.

${ }^{42}$ Article 8(1) Commission Delegated Regulation (EU) 2017/2359.

${ }^{43}$ Article 8(2) Commission Delegated Regulation (EU) 2017/2359.
} 
payment in relation to the services they have received". ${ }^{44}$ In any case, the amount of the inducement being paid should not be disproportionate and not excessive to the services being provided. ${ }^{45}$

EIOPA considers important that insurance intermediaries and insurance undertakings demonstrate compliance with Article 8 of Delegated Regulation 2017/2359, which requires the same to perform an overall analysis of the inducement schemes, taking into account any relevant factors that may increase or decrease the risk of detriment to customers. ${ }^{46}$ Regarding the frequency of such assessments, EIOPA recommends that "insurance intermediaries and insurance undertakings consider all relevant factors which may increase or decrease the risk of a detrimental impact on the quality of the relevant service to the customer or risk of impairing compliance with the intermediary's or insurance undertaking's obligation to act fairly, honestly and professionally in accordance with the best interests of the customer, and assess for themselves at what frequency the assessment is required in order to maintain continual compliance with the criteria set out in Article 29(2), IDD". For example, if there are no changes or modifications to the inducement scheme, the frequency can be appropriately extended, where no other indicators (such as customer complaints or others) give reason to do so. Anyway, the details of the assessment should be recorded in order to demonstrate and enable competent authorities to monitor that the inducement complies with the criteria set out in Article 29(2) IDD. ${ }^{47}$

Anyway, despite the ambition to set up a level playing field between IBIPs and other financial investments, IDD requirements for inducements are opposite to those applied by MiFID II. While inducements are banned unless explicitly permitted, the IDD presumes they are permitted and are prohibited if they determine a 'detrimental impact' on the distributor's quality of the service. ${ }^{48}$ A further dis-alignment with MiFID II refers to the absence of an enhanced regime in case of the distributor of an IBIP provides advice on an independent basis. Under the IDD, in fact, Member States have the discretion to introduce a specific regime in this respect to better protect investors. Again, differences between national implementation rules remain and as far as the distribution of the IBIP is concerned the gold plating measures have the effect of fragmenting the internal market in the financial services at large.

\footnotetext{
${ }^{44}$ EIOPA Q\&A on Regulation (2018), No. 1631.

${ }^{45}$ In this respect, EIOPA reiterates that in case of a rebate from a fund manager, insurance undertakings should consider again the already mentioned EIOPA's Opinion on monetary incentives and remuneration between providers of asset management services and insurance undertakings in which the risk of customer detriment related to the practice of receiving rebates from asset managers are addressed (Q\&A No. 1631),

${ }^{46}$ EIOPA Q\&A on Regulation (2018), No. 1623.

${ }^{47}$ Ibidem.

${ }^{48}$ Colaert and Incalza (2019), p. 386.
} 


\section{Demands and Needs Test}

IDD provides specific conduct of business rules, not derived this time from MiFID II regime, known as the demands and needs test. The scope of this test is not prescribed in the Directive or the Delegated Regulation and it is subject to national implementation. However, EIOPA has provided some guidance regarding minimum expectations for this test and how it may relate to the assessment of suitability. ${ }^{49}$ Recital 7 of Delegated Regulation 2017/2359 clarifies that the assessments of suitability and appropriateness are without prejudice to the obligation, for insurance intermediaries and insurance undertakings, to consider and specify, before the conclusion of any insurance contract, on the basis of information obtained from the customer, the demands and needs of that customer. The main information concerning the customer's needs, typically includes, for example, personal information (age, profession, place of residence, etc.) or the information particularly linked to the type of product requested. This information should enable the insurance intermediary or insurance undertaking to assess whether certain products can be offered or not, according to their capacity of meeting the demands and needs of the customer. This could lead to a selection of a range of comparable products for consideration during the suitability assessment where advice is being given or during the appropriateness assessment where no advice is given.

The 'demands and needs' test provides protection for customers to avoid cases of mis-selling (Recital 44, IDD), and it applies to all insurance contracts, not just IBIPs. Article 30, IDD applies "without prejudice" to the demands and needs test as covered by Article 20(1), IDD. The 'demands and needs' test has to be performed in any event prior to the conclusion of the contract and is distinct from the suitability assessment in advised cases, and the suitability assessment can also be provided at any time during the customer relationship. The evaluation of demands and needs is required whether or not advice is being provided and the specifying of the demands and needs would not amount to a suitability assessment. Depending on the national implementation, where advice is being provided, the demands and needs test and assessment of suitability could be seen as a continuum, rather than as a break. However, it is not clear whether a qualitative and timely suitability assessment would cover the demands and needs test. ${ }^{50}$ Since the 'demands and needs' test is subject to national implementation, a more extensive guidance from EIOPA would be in the interest to avoid the internal market fragmentation.

\footnotetext{
${ }^{49}$ EIOPA, Q\&A on Regulation (2018), No. 1638.

${ }^{50}$ Busch et al. (2019), p. 366.
} 


\section{Suitability and Appropriateness Assessment}

As already mentioned above, the insurance intermediary or insurance undertaking has, in addition, to gather, as part of the advice process, information about the customer's knowledge and experience in the relevant investment field, the customer's financial situation and his or her investment objectives, in order to be able to recommend to the customer insurance-based investment products that are suitable for the investor. In case of advice provided to the client, the distributor has to consider other more specific and detailed elements, like the customer's financial situation, including their ability to bear losses, their investment objectives, including their risk tolerance, and other correlated information. In the EIOPA view, the final outcome should be a personalised recommendation where it is specifically explained why that particular product best meets the customer demands and needs.

Under the IDD and its Delegated Regulation, ${ }^{51}$ the provisions concerning the assessment of suitability and appropriateness are almost identical to the corresponding provisions under MiFID II and its specific Delegated Regulation. ${ }^{52}$ In particular, the suitability assessment requires that the insurance intermediary or undertaking, in the case of sales with advice, gathers information about their client's knowledge, experience, investment objective and risk tolerance-in order to recommend to the client the IBIP that is best aligned with the client's profile. ${ }^{53}$ To be recommended, the IBIP has to meet the client's investment objectives, risk tolerance, financial situation and that its nature and characteristics are adequate with respect to the client's knowledge and experience. ${ }^{54}$

If the insurance product is not suitable for the individual customer or the suitability cannot be determined, but the customer still wishes to conclude the contract it is up to the Member State's implementation law to establish if the contract can still be concluded. In the EIOPA's view, Paragraphs 5 and 6 of Article 9 of the Delegated Regulation 2017/2359 cover the cases where a recommendation cannot be made due to the insurance intermediary or the insurance undertaking not obtaining the necessary information or there being no products that are suitable for the customer or potential customer. ${ }^{55}$ In these circumstances, the customer may agree to proceed with concluding the contract as a sale without advice (in conformity with the applicable rules of national law), and subject to an assessment of appropriateness unless it is possible to sell the contract on an execution only basis (see recital 12 of Delegated Regulation 2017/2359). Where the distributor cannot obtain the necessary information to assess the appropriateness of the contract, the distributor shall warn the customer that the contract might not be appropriate. Only when the customer asks to proceed with concluding the contract despite this warning, the distributor

\footnotetext{
${ }^{51}$ Article 30 IDD and Articles 9-19 Commission Delegated Regulation (EU) 2017/2359.

${ }^{52}$ Articles 9ff MiFID II and articles 54ff Commission Delegated Regulation (EU) 2017/565.

${ }^{53}$ Article 30(1) IDD and Article 9 Commission Delegated Regulation (EU) 2017/2359.

${ }^{54}$ Article 9(2) Commission Delegated Regulation (EU) 2017/2359.

${ }^{55}$ EIOPA Q\&A on Regulation (2018), No. 1639.
} 
may perform the sale. In all cases, Article 20(1) IDD provides that any contract proposed must always be consistent with the demands and needs of the customer. The insurance intermediary or undertaking should adopt measures to ensure that the information collected about the clients is reliable, and communicate to the same that the suitability assessment is performed in their best interest. ${ }^{56}$ It should then provide the customer with the so-called 'suitability statement', which includes an outline of the advice given, as well as information about how the recommendation meets the customer's investment objectives, risk tolerance, financial situation, knowledge and experience. $^{57}$

The appropriateness requirement provides that, in the event of sales requiring no advice, the insurance intermediary or insurance undertaking gathers information on the client to assess if the product or services offered or demanded were appropriate for the customer. ${ }^{58}$ In the event the product is deemed not appropriate for the customer, the insurance intermediary or insurance undertaking should warn the customer or potential customer. EIOPA believes that the level of detail will be case-specific and depend upon the individual circumstances of the sale including the nature of the product or service offered or demanded, the risks involved and the knowledge and experience of the customer. ${ }^{59}$ It is worth noting that Article 17(1) of Delegated Regulation 2017/2359 requires that the information obtained shall include information to the extent appropriate to the nature and type of product or service offered or demanded. Therefore, it should relate to the product overall, including where relevant, such as in the case of a unit-linked insurance contract, the underlying investment assets. Article 19(3) of Delegated Regulation 2017/2359 contains requirements for records to be kept in relation to the appropriateness assessment, in particular regarding the result of the assessment, warnings given to the customer and storage in an accessible manner for future reference. As under MiFID II, this assessment is not required concerning non-complex products as defined by MiFID II. ${ }^{60}$ However, due to the specific structures of insurance products, the Commission Delegated Regulation under IDD provides, among the criteria for non-complex IBIPs, an additional condition concerning products including a specific guarantee. ${ }^{61}$

Moreover, the insurance intermediary or insurance undertaking should establish a record of documents agreed with the customer containing rights and obligations of the parties, as well as other terms related to the provision of services to the customer. The customer should also be provided with periodic reports on the service, which include a number of communications proportionate to the type and complexity of the IBIP involved. ${ }^{62}$ In the context of periodic reporting to customers, the insurance

\footnotetext{
${ }^{56}$ Article 10 and 11 Commission Delegated Regulation (EU) 2017/2359.

${ }^{57}$ Article 14(1) Commission Delegated Regulation (EU) 2017/2359.

${ }^{58}$ Article 30(2) IDD and Article 14 Commission Delegated Regulation (EU) 2017/2359.

${ }^{59}$ EIOPA Q\&A on Regulation (2018), No. 1636.

${ }^{60}$ Article 30(3) IDD and 25(4)(a) MiFID II.

${ }^{61}$ Article 16(a) Commission Delegated Regulation (EU) 2017/2359.

${ }^{62}$ Articles 30(4) and (5) IDD.
} 
intermediary is also expected to develop and provide 'adequate reports on the service provided'. There could be some overlapping between the insurance intermediary primarily responsible for reporting to customers on costs and charges and providing periodic reports to customers, and the insurance undertaking which is always responsible for delivering information on the product, as required under the Solvency II Directive. According to EIOPA, with regard to the obligations to provide appropriate reporting under Articles 29(1) and 30(5), IDD and Article 18 of Delegated Regulation 2017/2359, it will depend upon who is providing the service. ${ }^{63}$ This may generally be expected to be an insurance intermediary, except where the insurance undertaking is providing services when distributing directly. Thus, the insurance undertaking remains always responsible for delivering information required by Article 185 of Directive 2009/138/EC (Solvency II). ${ }^{64}$

\section{Non-complex Insurance-Based Investment Products}

Drawing from the relevant provisions in the IDD (Articles 30(3) (a), 30(6)) and MiFID II (Article 57) although an assessment of the suitability or appropriateness of an IBIP for the customer by the insurance distributor is generally required as part of an advised or non-advised sale (IDD Article 30 (1),(2)), Member States are allowed (IDD Article 30(3)) to derogate from these obligations and not to require either a suitability or appropriateness test to be conducted, where various conditions are satisfied. Such sales ("execution-only") although carried out only at the initiative of the customer still require the insurance distributor to specify the demands and needs of the customer prior to the conclusion of the contract (IDD Article 20(1)). One of the conditions specified in Article 30(3) to determine whether an IBIP can be distributed as an execution-only sale relates to the complexity of the IBIP. IBIPs can be considered non-complex when they only provide investment exposure to the financial instruments deemed non-complex under MiFID II and do not incorporate a structure which makes it difficult for the customer to understand the risks involved (IDD article 30(3)(a)(i)).

In accordance with Article 25(8) of MiFID II, the Commission is empowered to adopt delegated acts on the criteria to identify "other non-complex financial instruments" referred to in Article 25(4)(a)(vi) of the same Directive. Also, Article 30(3) (a)(ii) of IDD acknowledges the possibility that IBIP may not fall within the scope of Article 30(3)(a)(i), but may still be deemed a non-complex product. EIOPA has considered that where an IBIP incorporates a structure which makes it difficult for the customer to understand the risks involved, it is in all cases not fit for distribution via an execution-only sale. ${ }^{65}$ EIOPA's evidence-gathering has shown that there are

\footnotetext{
${ }^{63}$ EIOPA, Q\&A on Regulation (2018), No. 1645.

${ }^{64}$ Articles 30(4) and (5) IDD.

${ }^{65}$ EIOPA 17/048, Technical Advice on Insurance Distribution Directive (1 February 2017), at 72ff.
} 
only a limited number of IBIP types currently sold on an execution-only basis. Whilst numerous Member States allow for the sale of certain products on a non-advised basis, only a limited number allow for products to be sold by means of execution-only transactions. In relation to the criteria for the assessment of other non-complex financial instruments, EIOPA has included in its technical advice the relevant provisions of the Commission Delegated Regulation under MiFID II, where these criteria address product features, which are considered to be equally applicable to IBIPs. However, in these cases, it has been still necessary to modify some of the MiFID II requirements to reflect the insurance sector appropriately. In particular, regarding the provision in point (d) of the technical advice, given that exit penalties have been a feature of long-term IBIPs that are considered to have led to consumer detriment, this is intended to exclude products with unreasonable exit charges, including fiscal penalties. Regarding the nature of any guarantee provided by the insurance undertaking, where the latter provides a guarantee regarding the surrender and maturity value of an IBIP, the customer is not fully exposed to the performance of the financial instruments in which the insurance undertaking has invested or to which the customer's benefits are linked. In view of this, depending on the nature of the guarantee, IBIPs could be regarded as non-complex, even though the contract may provide investment exposure that is not limited to financial instruments deemed non-complex under MiFID II. In this case, EIOPA has considered that, as a minimum, the customer should be guaranteed to receive, at both surrender and maturity, at least the amount of the premiums that they have paid, minus legitimate costs levied. ${ }^{66}$

In accordance, EIOPA has issued the following technical advice: "An IBIP shall be considered as non-complex for the purposes of Article 30(3)(a)(ii) of Directive (EU) 2016/97 if it satisfies all of the following criteria: (a) the contractually guaranteed minimum surrender and maturity value is at least the amount of premiums paid by the customer minus legitimate costs levied; (b) it does not incorporate a clause, condition or trigger that allows the insurance undertaking to materially alter the nature, risk or pay-out profile of the IBIP; (c) there are options to surrender or otherwise realise the IBIP at a value that is available to the customer; (d) it does not include any explicit or implicit charges which have the effect that, even though there are technical options to surrender the IBIP, doing so may cause unreasonable detriment to the customer, because the charges are disproportionate to the cost to the insurance undertaking of the surrender; (e) it does not in any other way incorporate a structure which makes it difficult for the customer to understand the risks involved". ${ }^{67}$

Contracts for IBIPs can be difficult to understand for consumers. Distributors, either insurance undertakings or insurance intermediaries, play therefore an important role in processing information for the consumer and guiding consumers in

\footnotetext{
${ }^{66}$ EIOPA 17/048, Technical Advice on Insurance Distribution Directive (1 February 2017), at 75-76.

${ }^{67}$ EIOPA 17/048, Technical Advice on Insurance Distribution Directive (1 February 2017), at 77.
} 
choosing suitable insurance policies. Prior to the advent of the IDD, consumer protection standards for the sales of insurance-based investment products were not considered sufficient at EU level to reduce the risk of mis-selling of those products, as the IMD did not contain specific rules for the sale of life insurance products with an investment element. This was in spite of the fact that these products are generally more complicated and present higher risks for retail consumers than other insurance products. Hence, IDD has stipulated additional conduct of business rules for the sale of IBIPs, and it provided for the case that differentiation should exist between complex and non-complex IBIPs.

Where an IBIP is considered non-complex, Member States may allow insurance distributors to not undertake some of the assessments (suitability and appropriateness) during the sales process that is normally necessary for the distribution of IBIPs. The EIOPA technical advice on the criteria to be used to assess "other non-complex IBIPs" aimed to facilitate the identification of "other non-complex IBIPs", such that only those products for which the risks are readily understood by customers, can be sold by execution-only. It also aimed to promote the consistent application of the IDD with respect to the identification of "other non-complex insurance-based investments" to be consistent with the line taken in the delegated acts expected to be adopted under Article 25(8) of MiFID II. Those aims are aligned with those under the IDD, i.e. the aim of improving insurance regulation in a manner that will facilitate market integration, the aim of establishing the conditions necessary for fair competition between distributors of insurance products and the aim of strengthening consumer protection, in particular with regards to IBIPs. It follows that an overly strict approach would not only be disadvantageous for insurance undertakings and insurance intermediaries, but also for customers and potentially for NCAs.

Hence, the adoption of criteria based on MiFID II seemed like the best solution in many respects, i.e. firstly because it was considered as striking the appropriate balance between the interests of insurance distributors and those of their customers and because it was considered as enabling the necessary flexibility at NCA level via the provision of criteria for other "non-complex insurance-based investments" at EU level. Not least, at the customer level, it seemed reasonable to prevent insurance undertakings and insurance intermediaries from making insurance products available for sale via execution-only which do not meet the criteria, while enabling customers to execute an order for products if the criteria are met. ${ }^{68}$

\footnotetext{
${ }^{68}$ EIOPA, Technical Advice on possible delegated acts concerning the Insurance Distribution Directive, 1/2/2017, EIOPA-17/048. About this part, please see Noussia and Siri (2019), p. $47 \mathrm{ff}$.
} 


\section{Sustainable Finance and IBIPs}

The EU initiatives for the promotion of sustainable finance ${ }^{69}$ - started in the end of 2016 with the appointment of the High-Level Expert Group (HLEG) on sustainable finance and formally launched in March 2018 with the adoption of the action plan on 'Financing Sustainable Growth', ${ }^{70}$ is going to reshape the regulatory framework related to the distribution of IBIPs, with particular regard, on the one hand, to disclosure rules, and on the other, to Solvency II and IDD framework in relation to the integration of sustainability preferences and considerations in rules concerning investment advice, prudent person principle, conflicts of interest and target market assessment.

As to the first aspect-disclosure rules-the new Regulation (EU) 2019/2088 ('ESG Disclosure Regulation') ${ }^{71}$ provides for financial market participants-including insurance undertakings which make available an $\operatorname{IBIP}^{72}$ - and financial advisers - comprising insurance intermediaries and insurance undertaking providing advice with regard to IBIPs ${ }^{73}$ - new sustainability-related disclosure duties towards end investors. In particular, the new rules, by applying a cross-sectorial approach, introduce a set of pre-contractual and on-going disclosure duties for a vast range of financial entities, concerning the consideration of sustainability factors, impacts and risks in the investment decision-making and advisory processes. The main aim of the regulation, aside from the reduction of market fragmentation and inefficiencies, ${ }^{74}$ is the diminution of information asymmetries that could ultimately prevent end investors from making fully informed investment decisions. ${ }^{75}$ As a consequence, transparency duties are imposed to financial market participants and financial advisers in relation to: (i) the integration of sustainability risks ${ }^{76}$ in investment decision-making processes or investment/insurance advice ${ }^{77}$ and in their remuneration policies; ${ }^{78}$ (ii) the consideration of adverse sustainability impacts of their decision-making/

\footnotetext{
${ }^{69}$ Siri and Zhu (2019), pp. 1-23.

${ }^{70}$ EU Commission Communication, Action Plan: Financing Sustainable Growth, COM (2018) 97 final (March 2018).

${ }^{71}$ Regulation (EU) 2019/2088 of 27 November 2019 on sustainability-related disclosures in the financial services sector disclosure regulation.

${ }^{72}$ Article 2(1)(a) ESG Disclosure Regulation.

${ }^{73}$ Article 2(11)(a)(b) ESG Disclosure Regulation. It should be noted that Art. 17 exempts financial advisers which employ fewer than three persons from the application of the regulation.

${ }^{74}$ Recital 9 ESG Disclosure Regulation.

${ }^{75}$ Recitals 9, 10 and 20 ESG Disclosure Regulation.

${ }^{76}$ 'Sustainability risk' is defined as "an environmental, social or governance event or condition that, if it occurs, could cause an actual or a potential material negative impact on the value of the investment”. Article 2(22) ESG Disclosure Regulation.

${ }^{77}$ Articles 3 and 6 ESG Disclosure Regulation.

${ }^{78}$ Article 5(1) ESG Disclosure Regulation.
} 
advisory processes and at the financial product level ${ }^{79}$ the (iii) the subsistence of sustainable investment ${ }^{80}$ as the main objective of a financial product; ${ }^{81}$ and (iv) the promotion of environmental or social characteristics in investment decision-making and in advisory processes. ${ }^{82}$

Such rules-which will apply as from 10 March 2021-will undoubtedly enhance transparency and prevent the diffusion of green-washing practices. However, the effectiveness of the new regulation is strictly connected to the prior finalization of the regulation on the establishment of a framework to facilitate sustainable investment (the 'Taxonomy Regulation'), which will establish uniform criteria to determine whether an economic activity is to be considered sustainable.

As to the second aspect, on 30 April 2019 EIOPA published the technical advice to the EU Commission ${ }^{83}$ on the integration of sustainability risks and factors in the delegated acts under Solvency II and the IDD with specific reference to organizational requirements, operating conditions, risk management (under Solvency II), and target market assessment (under IDD). ${ }^{84}$ It should be noted that, for the preparation of the technical advice, EIOPA has closely liaised with ESMA to ensure consistency across sectors to the extent possible. ${ }^{85}$ A first key proposal is made in relation to the integration of sustainability in the prudent person principle of Article 132 of the Solvency II Directive, within which insurance and reinsurance undertakings shall take into account sustainability risks when assessing the security, quality, liquidity, and profitability of the portfolio as a whole. In particular, EIOPA calls for the introduction of new requirements concerning the integration of sustainability risks by insurance and reinsurance undertakings in their investment decisions and underwriting practices, as well as the consideration of the potential long-term impact of their investment strategy and decisions on sustainability factors. ${ }^{86}$

\footnotetext{
${ }^{79}$ Article 4 and 7 ESG Disclosure Regulation.

${ }^{80} \mathrm{~A}$ 'sustainable investment' is defined as "an investment in an economic activity that contributes to an environmental or [...] to a social objective [...], provided that such investments do not significantly harm any of those objectives and that the investee companies follow good governance practices [...]. Recital 17 ESG Disclosure Regulation.

${ }^{81}$ Articles 9, 10 and 11 ESG Disclosure Regulation.

${ }^{82}$ Articles 10 and 11 ESG Disclosure Regulation.

${ }^{83}$ On 24 July 2018, the European Supervisory Authorities received a formal request from the Commission to provide technical advice supplementing the initial package of proposals and to assist the Commission on potential amendments to, or introduction of, delegated acts under Directive 2009/65/EC (UCITS), Directive 2009/138/EC (Solvency II), Directive 2011/61/EU (AIFM), Directive 2014/65/EU (MiFID II) and Directive 2016/97/EU (Insurance Distribution Directive-IDD) with regard to the integration of sustainability risks and sustainability factors. See Letter from DG FISMA on sustainability risks and factors, FISMA C4 SG/acg (2018)4365900. ${ }^{84}$ EIOPA (2019) Technical Advice on the integration of sustainability risks and factors in the delegated acts under Solvency II and IDD, 30/04/2019, EIOPA-BoS-19/172.

${ }^{85}$ EIOPA (2019) Technical Advice on the integration of sustainability risks and factors in the delegated acts under Solvency II and IDD, 30/04/2019, EIOPA-BoS-19/172, at 4.

${ }^{86}$ EIOPA (2019) Technical Advice on the integration of sustainability risks and factors in the delegated acts under Solvency II and IDD, 30/04/2019, EIOPA-BoS-19/172, at 25.
} 
Further amendment proposals concern conflict of interests rules under the IDD, as EIOPA calls for the integration of ESG considerations in the identification of conflicts of interest whose existence may damage the interests of the customer, and suggests that when insurance distribution is carried out in relation to IBIPs, insurance undertakings and insurance intermediaries should take all appropriate steps to identify and manage any conflicts of interest that may arise in relation to ESG considerations and in the course of any insurance distribution activities. ${ }^{87}$ In respect to product oversight and governance, EIOPA calls for the amendment of the IDD Delegated Regulation 2017/2358, suggesting the introduction of a clear reference to ESG considerations and preferences. In particular, according to EIOPA's policy proposals, ESG factors should be taken into account by manufacturers throughout the entire target market assessment of each insurance product, but also in the context of product testing, monitoring and review processes and with regard to distribution arrangements. ${ }^{88}$

Finally, on 4 January 2019, the European Commission published draft rules to ensure-by amending the IDD — that investment firms and insurance distributors take sustainability considerations and preferences into account when providing advice to their clients on IBIPs. ${ }^{89}$ In particular, the Commission proposed to amend the IDD by requiring insurance intermediaries and insurance undertakings to assess their customers and potential customers' ESG preferences as a part of their suitability assessment, but also to explain in the suitability statement provided to customers how their recommendation took into account such preferences. The new delegated regulation has not been published yet, but it will enter into force 20 days after its publication on the Official Journal of the European Union and will apply 18 months after it enters into force.

However, some commentators raised many concerns with such proposal, especially in relation to the concept of 'ESG preferences', defined by the delegated regulation as "a customer's or potential customer's choice as to whether and which environmentally sustainable investments, social investments or good governance investments should be integrated into his/her investment strategy". ${ }^{90}$ In particular, many stakeholders required further clarification or even substitution of such wording, since its vagueness could lead to divergent approaches by retailers and

\footnotetext{
${ }^{87}$ EIOPA (2019) Technical Advice on the integration of sustainability risks and factors in the delegated acts under Solvency II and IDD, 30/04/2019, EIOPA-BoS-19/172, at 33. See Marano (2019), pp. $59 \mathrm{ff}$.

${ }^{88}$ EIOPA (2019) Technical Advice on the integration of sustainability risks and factors in the delegated acts under Solvency II and IDD, 30/04/2019, EIOPA-BoS-19/172, at 37.

${ }^{89}$ Draft Commission Delegated Regulation (EU) ....... amending Delegated Regulation (EU) 2017/2359 with regard to environmental, social and governance preferences in the distribution of insurance-based investment products.

${ }^{90}$ Draft Commission Delegated Regulation (EU) .../... amending Delegated Regulation (EU) 2017/2359 with regard to environmental, social and governance preferences in the distribution of insurance-based investment products, Article 1(1).
} 
ultimately to increased confusion among clients. ${ }^{91}$ Moreover, such definition seems inconsistent with the one provided in the draft delegated regulation amending MiFID II, as it seems to assume that all customers have ESG preferences, while it should be clarified-as done in the draft delegated regulation amending MiFID II-that customers may or may not have ESG preference. ${ }^{92}$

As one may infer from this brief overview of EU legislative proposals and measures on sustainable finance, the integration of ESG considerations, risks and preferences in the distribution of IBIPs requires, again, the challenging implementation of a cross-sectorial approach, where the need for legal certainty has to coordinate with the flexibility required in the light of the peculiarities of each financial sector and of the novelty of the still-evolving sustainable financial market.

\section{Policy Issues and Next Steps}

As outlined in the introduction, current IBIPs investor protection rules in EU legislation rely on sectoral rules largely derived from the MiFID II paradigm. The "silo" approach is, at least partially, a consequence of the market structure at the level of distributors of insurance-based financial products. The long-term horizon of life insurance products as well as the variety of distribution channels in life insurance markets, including agents and brokers, need flexibility and proportionality in respect of intermediaries providing advice in the financial sector. ${ }^{93}$ However, significant differences between the legal frameworks affect the decision-making of retail investors. In particular, the rules related to disclosure, suitability assessment and inducements, may not work as intended and probably affect the decision-making of retail investors when they shop around for savings product. ${ }^{94}$

At the same time, the PRIIPs "horizontal" framework has proven somehow not adequate to address the legal differences across the variety of retail investment products. As others have already observed, the existing protection regime may result in efficiency losses and information asymmetries. As regards these shortcomings, a cross-sectoral mapping exercise could identify possible redundancies, inconsistencies, overlaps and gaps and evaluate the extent to which those issues could hinder retail investors from taking sound investment decisions. This comparison may add

\footnotetext{
${ }^{91}$ See feedbacks on Commission Delegated Regulation (EU) .... . . amending Delegated Regulation (EU) 2017/2359 with regard to environmental, social and governance preferences in the distribution of insurance-based investment products, available at https://ec.europa.eu/info/law/ better-regulation/have-your-say/initiatives/1185-Institutional-investors-and-asset-managers-dutiesregarding-sustainability/feedback?p_id=237222.

${ }^{92}$ Draft Commission Delegated Regulation (EU) .../. . o of XXX amending Delegated Regulation (EU) 2017/565 as regards the integration of Environmental, Social and Governance (ESG) considerations and preferences into the investment advice and portfolio management.

${ }^{93}$ Pscheidl (2018), p. 211 ss.

${ }^{94}$ Busch et al. (2019), p. 343 ss.
} 
value to a review of the existing disclosure regime only if the type of the legislative instrument applied in each piece of the current rules is also included in the scope. For instance, as described above, rules on pre-contractual and on-going disclosure requirements are set out in the MiFID II, IDD, PRIIPs, Solvency II, as well as in national legislation. Without a common core at EU level, hopefully, encapsulated in an EU Regulation, a further step in the harmonisation process would be proven costly and ultimately unsatisfactory. As a benchmark, the new pre-contractual and on-going disclosure requirements set out in the PEPP Regulation should be tested to uniform the comparability of information items, both across products and across the Member States. The new PEEP information document may represent a tool to assess the clarity and comprehensiveness of the information documents of the IBIPs as well the other PRIIPs products.

Notwithstanding the merits of a deep cross-sectoral harmonisation of all the information documents in scope of the PRIIPs Regulation, a further step to enhance the investor protection at least in the insurance sector for all the IBIPs products rely on the different approaches at national level related to the rules for the demands and needs test and the suitability assessment for retail investors. The IDD does not provide strict rules for the timing of the suitability assessments, presumably assuming that before each transaction with a client both a 'demands and needs' test and a suitability assessment have to be performed by the distributor. As the corresponding MiFID II rules show, the information gathered from a client may be part of a portfolio of data covering different transactions. Thus, a further step should be to provide clear rule enabling and encouraging the distributor to undertake one suitability assessment for more than one transaction.

Moreover, it would be highly recommended to rethink the process of collecting information through the demands and needs test or the suitability assessment from 'a client perspective'. If the questionnaires to be answered by retail investors are compiled with the assistance, and somehow under the influence of the distributor, uniform guidelines should be provided, as for financial instruments under the MiFID II/MIFIR package, to enhance the effectiveness of the information collection. Under MiFID II, a firm is entitled to rely on the information provided by retail clients and must take reasonable steps to ensure that the information collected is reliable. ${ }^{95}$ The actual high-level Delegated Regulation should be complemented by EIOPA Guidelines with the aim of increasing the effectiveness of the 'demands and needs' test or the suitability assessment from a client perspective and foster the supervisory convergence between a variety of market practices at the national level.

Among others, the IBIPs Guidelines we propose should include the means used to gather information about the retail investor with proper guidance depending on the way adopted to collect the information. According to behavioural studies, the guidelines should be specifically designed to be applied to a written questionnaire, or online profiling with or without human interaction, or by means of an interview.

\footnotetext{
${ }^{95}$ ESMA (2018) Guidelines on certain aspects of the MiFID II suitability requirements, 6/11/2018, ESMA 35-43-1163.
} 
Furthermore, the information needed with regards to the retail investor's knowledge and experience, financial situation and investment objectives should be identified and the style of the advisory dialogue should also be set, in terms of the clarity and comprehensibility of the questions posed relating the preferences, economic situation, and risk-profile.

A further step to enhance the quality of the process of the collection of information from a client perspective requires special attention to the comprehensibility of the suitability reports and the suitability statements. ${ }^{96}$ The IDD Level 2 Delegated Regulation should be complemented by guidelines recognising good market practices about the comprehension and usefulness of the suitability reports and suitability statements provided to retail investors. Furthermore, from a client perspective, not only the content and the information needed should be identified but we also need to ensure the clarity and comprehensibility for the retail investor of such information, also as regards the decision to choose the more costly or complex financial instrument over an equivalent one.

\section{Conclusion}

The chapter has aimed to analyse the recent reform of the EU regulatory framework in regard to IBIPs. The actual regime provided for IBIPs offers stronger protection to all customers, regardless of the distribution channel. In line with the EU plan to provide consistent cross-sectorial investor protection across all Member States, many provisions under the IDD are based on the corresponding rules under MiFID II, even though some differences remain and should be further elaborated in connection to the inconsistencies, overlaps and gaps in the investor protection as far as the distribution of the IBIPs is concerned. Furthermore, several Member States have exercised the discretions given by the IDD for the IBIPs mainly to gold plate investor protection measures. However, such an uncoordinated approach undermines the internal market. Therefore, the chapter advises EIOPA to use its powers to coordinate the diverging Member States' measures and ensure transparency about the measures NCAs have taken in this respect.

The European Commission is already required to review, by 2021, the IDD, assessing the specific characteristics of insurance-based investment products. Focusing on the long-term purpose and the variety of insurance-based investment products, we need to design and implement a tailored regime combining life insurance products regulation and conduct of business rules under a cross-sectorial regulatory framework of investor protection.

\footnotetext{
${ }^{96}$ Article 14 (1), (2) and (3) Commission Delegated Regulation (EU) 2017/2359.
} 


\section{References}

Busch D (2016) Product governance and product intervention under MiFID II/MiFIR. In: Busch D, Ferrarini G (eds) Regulation of the EU financial markets: MiFID II and MiFIR. Oxford University Press, pp 123-146

Busch D, Colaert V, Hellinger G (2019) As 'assist-your-customer obligation' for the financial sector? In: Colaert V, Busch D, Incalza T (eds) European financial regulation. Levelling the cross-sectoral playing field. Hart Publishing, pp 343-375

Clarck R (1976) The soundness of financial intermediaries. Yale Law J 86(1):4-103

Colaert V (2016) The regulation of PRIIPs: great ambition, insurmountable challenges. J Financ Regul 2(2):203-224

Colaert V (2017a) Building blocks of investor protection: all-embracing regulation tightens its grip. J Eur Consum Mark Law 6:229-244

Colaert V (2017b) MiFID II in relation to other investor protection regulation: picking up the crumbs of a piecemeal approach. In: Busch D, Ferrarini G (eds) Regulation of the EU financial markets: MiFID II and MiFIR. Oxford University Press, pp 589-611

Colaert V (2019) Product information for banking, investment and insurance product. In: Colaert V, Busch D, Incalza $\mathrm{T}$ (eds) European financial regulation. Levelling the cross-sectoral playing field. Hart Publishing, pp 303-315

Colaert V, Incalza T (2019) Conflicts of interest and inducement in the financial sector. In: Colaert V, Busch D, Incalza T (eds) European financial regulation. Levelling the cross-sectoral playing field. Hart Publishing, pp 377-393

Della Negra F (2019) MiFID II and private law. Hart

Dreher M (2019) Produktfreigabeverfahren und Versicherungsaufsichtstrecht. In Dreher M, Wandt M (eds) Das interne Produckfreigabeverfahren Solvency II in der Rechtsanwendung, 2018. VVW GmbH, Karlsruhe, pp 79-122

Hofmann A, Neumann JK, Pooser D (2018) Plea for uniform regulation and challenges of implementing the new Insurance Distribution Directive. Geneva Pap Risk Insur Issues Pract 43:740-769

Kern A (2018) Marketing, sale and distribution. Mis-selling of financial products. A study requested by the ECON Committee, Directorate-General for Internal Policies PE 618.996

Köhne T, Brömmelmeyer C (2018) The new insurance distribution regulation in the EU-a critical assessment from a legal and economic perspective. Geneva Pap Risk Insur Issues Pract 43:704-739

Kyriaki N, Siri M (2019) The legal regime and the relevant standards. In: Marano P, Rokas I (eds) Distribution of insurance-based investment products. Springer, Cham, p 39 ss

Liverse K (2016) The scope of MiFID II. In: Busch D, Ferrarini G (eds) Regulation of the EU financial markets: MiFID II and MiFIR. Oxford University Press, pp 27-48

Marano P (2019) The product oversight and governance: standards and liabilities. In: Marano P, Rokas I (eds) Distribution of insurance-based investment products. Springer, Cham, pp 59-96

Moloney N (2010) How to protect investors. Lessons from the EC and the UK. Cambridge University Press

Moloney N (2014) EU securities and financial markets regulation. Oxford University Press

Moloney N (2015) Regulating the retail markets. In: Moloney N, Ferran E, Payne J (eds) The Oxford handbook of financial regulation. Oxford University Press, pp 736-765

Noussia K (2019) The legal framework regarding the distribution of insurance-based investment products: the EU and UK approach. J Int Bank Law Regul 33(4):119-136

Noussia K, Siri M (2019) The legal regime and the relevant standards. In: Marano P, Rokas I (eds) Distribution of insurance-based investment products. Springer, Cham, pp 27-58

Pscheidl D (2018) Implementing IDD across the EU—first findings and the way forward. ERA Forum 19:205-217

Ramharter M (2016) Aktuelle und zukünftige Fragen der Lebensversicherung zwischen Zivil- und Aufsichtsrecht - Information und Beratung nach der Richtlinie (EU) 2016/97 über Versicherungsvertrieb. ZVersWiss 105:221-254 
Rokas I, Siafarika A (2019) The notion of insurance-based investment products. A cross-sectoral legal approach in Europe. In: Marano P, Rokas I (eds) Distribution of insurance-based investment products. Springer, Cham, pp 3-25

Siri M, Zhu S (2019) Will the EU Commission successfully integrate sustainability risks and factors in the investor protection regime? A research agenda. Sustainability 11:1-23

\section{Legislation and Other Legal Instruments}

EIOPA (2017) Technical Advice on possible delegated acts concerning the Insurance Distribution Directive, 1/2/2017, EIOPA-17/048

EIOPA (2017) Opinion on Monetary Incentives and Remuneration Between Providers of Asset Management Services and Insurance Undertakings, 17/295

EIOPA (2018) Q\&A on Regulation (EU) No 2017-2359

EIOPA (2019) Technical Advice on the integration of sustainability risks and factors in the delegated acts under Solvency II and IDD, 30/04/2019, EIOPA-BoS-19/172

ESMA (2018) Guidelines on certain aspects of the MiFID II suitability requirements, 6/11/2018, ESMA 35-43-1163

EIOPA, Costs and past performance, 2020 Report, April 2020

EU Commission Communication, Action Plan: Financing Sustainable Growth, COM (2018) 97 final (March 2018)

EU Commission Delegated Regulation (EU) 2017/565 of 25 April 2016 supplementing Directive 2014/65/EU of the European Parliament and of the Council as regards organisational requirements and operating conditions for investment firms and defined terms for the purposes of that Directive

EU Commission Delegated Regulation (EU) 2017/2359 of 21 September 2017 supplementing Directive (EU) 2016/97 of the European Parliament and of the Council with regard to information requirements and conduct of business rules applicable to the distribution of insurance-based investment products

EU Commission Delegated Regulation (EU) 2017/2358 of 21 September 2017 supplementing Directive (EU) 2016/97 of the European Parliament and of the Council with regard to product oversight and governance requirements for insurance undertakings and insurance distributors

EU Draft Commission Delegated Regulation (EU) ....... amending Delegated Regulation (EU) 2017/2359 with regard to environmental, social and governance preferences in the distribution of insurance-based investment products

EU Draft Commission Delegated Regulation (EU) . . . . . o of XXX amending Delegated Regulation (EU) $2017 / 565$ as regards the integration of Environmental, Social and Governance (ESG) considerations and preferences into the investment advice and portfolio management

EU Directive 2004/39/EC of 21 April 2004 on markets in financial instruments amending Council Directives 85/611/EEC and 93/6/EEC and Directive 2000/12/EC of the European Parliament and of the Council and repealing Council Directive 93/22/EEC (MiFID I)

EU Directive 2009/138/EC of 25 November 2009 on the taking-up and pursuit of the business of Insurance and Reinsurance (Solvency II)

EU Directive 2014/65/EU of 15 May 2014 on markets in financial instruments and amending Directive 2002/92/EC and Directive 2011/61/EU (MiFID II)

EU Directive 2016/97/EU of 20 January 2016 on insurance distribution (IDD)

EU Regulation 1286/2014/EU of 26 November 2014 on key information documents for packaged retail and insurance-based investment products (PRIIPs)

EU Regulation 2019/2088/EU of 27 November 2019 on sustainability-related disclosures in the financial services sector disclosure regulation 
Open Access This chapter is licensed under the terms of the Creative Commons Attribution 4.0 International License (http://creativecommons.org/licenses/by/4.0/), which permits use, sharing, adaptation, distribution and reproduction in any medium or format, as long as you give appropriate credit to the original author(s) and the source, provide a link to the Creative Commons licence and indicate if changes were made.

The images or other third party material in this chapter are included in the chapter's Creative Commons licence, unless indicated otherwise in a credit line to the material. If material is not included in the chapter's Creative Commons licence and your intended use is not permitted by statutory regulation or exceeds the permitted use, you will need to obtain permission directly from the copyright holder. 